\title{
TEKNIK RESPONSIVE WEB DESIGN (RWD) SERTA PENERAPANNYA DALAM RANCANG BANGUN LAYOUT WEB
}

\author{
Miftah Faroq Santoso \\ Program Studi Magister Ilmu Komputer \\ Sekolah Tinggi Manajemen Informatika dan Komputer Nusa Mandiri \\ http://www.nusamandiri.ac.id \\ miftah_fs@yahoo.com

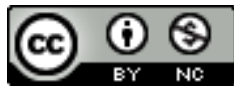

Ciptaan disebarluaskan di bawah Lisensi Creative Commons Atribusi-NonKomersial 4.0 Internasional.

\begin{abstract}
Technology development make influences the way to access the internet, which generally uses Desktop and Notebook computers, giving to other alternatives, namely accessing the internet using Tablets and Smartphones. The problem is that the majority of web layout designs cannot adjust the layout size automatically for these devices, because the resolution size of each device is different. To overcome the existing problems, we need a responsive web design method and technique in order to produce web layouts that can adjust the size of screen resolution automatically. The method used by applying the concept of Responsive Web Design (RWD), so that web layouts can adapt to screen size. Responsive web design techniques can be done in several ways, including using manual techniques using CSS Media Query and implementing CSS Frameworks such as Bootstrap CSS. The test results showed that the implementation of responsive web layouts using Bootstrap was very effective and efficient, because web designers only needed the main library from Bootstrap, which was then combined by modifying according to the wishes of the user.
\end{abstract}

Keywords: responsive, web, css, framework

Intisari-Perkembagan teknologi ikut mempengaruhi cara mengakses internet yang pada umumnya menggunakan komputer Desktop maupun Notebook, memunculkan alternatif lain yaitu mengakses internet dengan menggunakan Tablet dan Smartphone. Yang menjadi kendala adalah mayoritas desain layout web tidak dapat menyesuaikan ukuran layout secara otomatis terhadap perangkat tersebut, dikarenakan ukuran resolusi setiap perangkat berbeda. Untuk mengatasi permasalahan yang ada, diperlukan sebuah metode dan teknik desain web responsif agar dapat menghasilkan layout web yang dapat menyesuaikan ukuran resolusi layar secara otomatis. Metode yang digunakan dengan menerapkan konsep Responsive Web Design (RWD), agar layout web dapat beradaptasi terhadap ukuran layar. Teknik desain web responsif dapat dilakukan dengan beberapa cara, diantaranya dapat menggunakan teknik manual dengan menggunakan Media Query CSS dan pengimplementasian Framework CSS seperti Bootstrap CSS. Hasil pengujian didapatkan implementasi layout web responsif dengan menggunakan Bootstrap sangat efektif dan efisien, karena desainer web hanya memerlukan library utama dari Bootstrap, yang kemudian dipadukan dengan memodifikasi sesuai dengan keinginan pengguna.

Kata Kunci: responsif, web, css, framework.

\section{PENDAHULUAN}

Pada era modern sekarang ini perkembangan dalam mendesain sebuah website begitu cepat dan pesat mengalami perubahan. Mulai dari mendesain layout dengan hanya menggunakan tabel, hingga saat ini menggunakan CSS (Cascading Style Sheet) yang berfungsi sebagai penghias sekaligus pengatur gaya tampilan layout supaya dapat terlihat menarik dan elegan. Tahun 2007 perusahaan Apple memperkenal ponsel pintar (smartphone) iPhone, yang merupakan tonggak sejarah baru, mereka memberikan pengalaman baru bagi pengguna internet bagaimana berselancar didunia maya dengan cara yang berbeda, yaitu dengan menggunakan smartphone dengan ukuran layar yang tidak lebih dari 5 inci.

Mengakses halaman web melalui perangkat mobile akan berbeda secara tampilan, jika dibandingkan pada saat mengakses halaman web dengan menggunakan komputer Desktop dan Notebook, karena jenis perangkat tersebut memiliki resolusi ukuran yang berbeda. Ukuran resolusi pada layar Desktop, Notebook dan Tablet 
memiliki ukuran yang lebih besar jika dibandingkan resolusi layar yang terdapat pada Smartphone. Yang menjadi kendala adalah mayoritas halaman web yang ada masih menerapkan konsep fix-width design, atau layout web dengan ukuran lebar tetap, dapat dikatakan layout web belum dapat menyesuaikan ukuran layar secara otomatis berdasarkan perangkat yang yang digunakan. Hal ini menyebabkan pengguna harus mengatur ukuran halaman web, agar tampil secara maksimal. Hal ini menuntut para desainer web untuk mendesain tampilan sebuah web agar dapat menyesuaikan dibeberapa layar sekaligus atau lebih dikenal dengan Responsive Web Design (RWD). Sebuah website harus dapat merespon alat pengaksesnya dari mulai layar lebar, hingga layar kecil. Tuntutan responsif pun tidak mengada-ada, mengingat saat ini telah beredar perangkat bergerak (mobile devices) seperti smartphone, tablet, netbook, dan produk-produk sejenis di seluruh penjuru dunia (Anugerah, 2013).

Adapun manfaat dan tujuan dari penggunaan teknik responsif pada saat membangun sebuah layout web adalah agar website tersebut dapat secara otomatis mendeteksi dan mengetahui, perangkat jenis apa yang sedang digunakan, serta dapat mengetahui segala jenis ukuran layar yang bervariasi. Maka akan didapatkan tampilan layout web yang secara otomatis dapat menyesuiakan ukuran layar, dengan tetap memperhatikan fitur-fitur dari sebuah halaman web, tanpa merubah isi dari web tersebut.

Dalam penelitian ini digunakan metode teknik Responsive Web Design (RWD), agar layout web dapat menyesuikan terhadap ukuran layar secara otomatis, diantaranya dapat menggunakan teknik manual dengan menggunakan Media Query CSS atau dapat menggunakan Framework CSS seperti Bootstrap dan Foundation Framework (Anugerah, 2013). Namun pada penelitian ini dibatasi hanya menggunakan Framework CSS Bootstrap versi 4 di dalam pembuatan perancangan layout web responsif. Serta sebagai tools pendukung digunakan Sublime Text sebagai editor dan Mozilla, Chrome yang digunakan sebagai browser, untuk mensimulasikan tampilan website.

Hasil yang diharapkan tentunya dengan menggunakan teknik Responsive Web Design ( $R W D$ ), kenyamanan dalam berselancar didunia maya memberikan pengalaman yang berbeda bagi pengguna, ketika mengakses sebuah web, baik di komputer, smartphone dan tablet, namun akan tetap mendapatkan tampilan yang sama, meskipun diakses pada perangkat yang berbeda, yang memiliki ukuran layar yang bervariasi, dengan tidak menghilangkan kualitas tampilan dan estetika dari desain sebuah web.

\section{BAHAN DAN METODE}

Pada bagian paper ini akan dijelaskan seputar metode penelitian dan perancangan desain.

\section{Alat dan Bahan}

Adapun sebagai bahan (tools) pendukung yang digunakan dalam perancangan desain layout web responsif ini, terbagi menjadi dua, yaitu perangkat lunak (software) dan perangkat keras (hardware).

Tabel 1. Spesifikasi Software dan Hardware

\begin{tabular}{|c|c|c|}
\hline No & Alat (tools) & Keterangan \\
\hline 1 & $\begin{array}{l}\text { Perangkat Lunak } \\
\text { (Software) } \\
\text { a. Sublime Text } \\
\text { b. Mozilla/ Chrome }\end{array}$ & $\begin{array}{l}\text { Editor } \\
\text { Pengujian dan } \\
\text { simulasi }\end{array}$ \\
\hline 2 & $\begin{array}{l}\text { Perangkat Keras } \\
\text { (Hardware) } \\
\text { a. } 1 \text { Unit PC/ Laptop } \\
\text { b. Mouse, monitor, } \\
\quad \text { keyboard } \\
\quad \text { (peripheral) } \\
\text { c. Ponsel }\end{array}$ & $\begin{array}{l}\text { Spesifikasi PC } \\
\text { Standar } \\
\text { minimal: RAM } \\
\text { 2G, HDD 80G } \\
\text { Ujicoba pada } \\
\text { ponsel Lenovo } \\
\text { dengan OS } \\
\text { Android }\end{array}$ \\
\hline
\end{tabular}

Sumber: (Santoso, 2019)

\section{Metode}

Metodologi penelitian ini dilakukan dengan beberapa tahapan, diantaranya:

A. Studi literatur

Pada tahap awal dilakukan studi terhadap beberapa artikel dan buku, yang berkaitan dengan perancangan desain web responsif, Bootstrap CSS Framework. Pada tahap ini juga dilakukan untuk menemukan fokus persoalan serta perumusan solusi yang akan ditawarkan pada penelitian ini.

B. Analisis permasalahan dan perumusan hipotesis.

Setelah didapatkan bahan literatur, pada tahap ini dilakukan analisis untuk merumuskan sebuah solusi yang akan ditawarkan.

C. Perancangan solusi

Pada tahap ini, akan diawali dengan perancangan sebuah desain yang akan dijadikan sebuah solusi dari permasalahan yang diangkat.

D. Implementasi solusi dan uji coba

Penerapan solusi dari perancangan yang telah dilakukan, akan diujikan dengan mengimplementasikan ke dalam kode pemrograman. 
E. Penarikan kesimpulan

Hasil pengujian kemudian dianalisis untuk mendapatkan rumusan beberapa kesimpulan yang dapat diambil dari penelitian.

\section{Perancangan Desain}

Di dalam penelitian ini pembuatan layout web menggunakan teknik dan konsep Responsive Web Design. Dalam menggunakan teknik responsive web, caranya sangat bervariasi diantaranya dengan menggunakan teknik manual seperti Media Query CSS atau dengan menggunakan CSS Framework seperti Bootstrap dan Foundation.

A. Responsive Web Design (RWD)

Terminologi Responsive Web Design (RWD), kali pertama dipekernalkan oleh Ethan Marcotte ditahun 2010, di dalam artikel webnya yang berjudul "A book apart" (M. SOEKARNO PUTRA, 2017). Responsif desain web memungkinkan pengguna berselancar di internet dengan menggunakan berbagai perangkat (multi device) seperti smartphone, tablet atau laptop selain komputer desktop. Karena desainya yang dapat menyesuaikan serta dapat beradaptasi dengan berbagai ukuran layar, maka dikenal juga dengan istilah fluid design, elastic layout, rubber layout, liquid design, adaptive layout, cross-device design, dan flexible design (Bryant \& Jones, 2012).

Viewport merupakan salah satu fungsi paling penting yang terdapat pada desain responsif, viewport digunakan untuk menset ukuran layar sesuai dengan piranti yang sedang digunakan (Winarno \& Zaki, 2015). Ukuran akan disesuaikan dengan ukuran layar, artinya pengungjung akan men-zoom konten untuk melihat lebih detail. Berikut ini tampilan viewport pada browser, akan terlihat seperti gambar 1 dibawah ini:

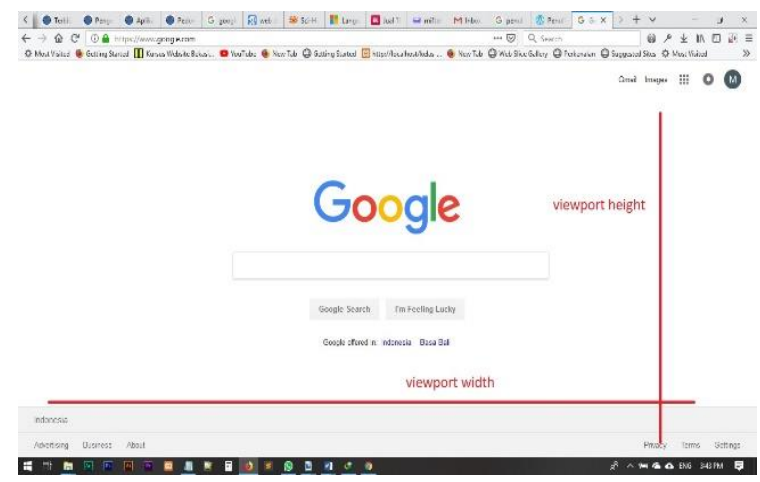

Sumber: (Santoso, 2019)

Gambar1. Width dan Height dari Viewport

Untuk sintaks penulisan meta tag name viewport, seperti berikut ini: <meta name="viewport" content="width=devicewidth">

Terdapat tiga konsep yang sangat penting di dalam teknik penggunaaan responsif web, diantaranya: a) Media Query dan Resolusi Layar b) Fluid Grid Layout c) Flexible Images dan Media (Baturay \& Birtane, 2013).

\section{B. Media Query CSS}

Media Query sangat erat kaitannya dengan resolusi layar dan merupakan salah satu komponen utama dari desain responsif, karena memungkinkan desainer web menargetkan style CSS secara spesifik berdasarkan ukuran piranti. Jadi desainer web memiliki kontrol penuh terhadap CSS yang memungkinkan mendesain satu layout website untuk digunakan dibeberapa platform sekaligus (Winarno \& Zaki, 2015). Terdapat beberapa tipe query salah satu diantaranya adalah: width | min-width | maxwidth, perintah query ini memungkinkan menargetkan style pada width dari viewport browser, juga dapat menargetkan width minimum dan maksimum. Untuk sintaks penulisan media query, akan terlihat seperti berikut ini:

@media only screen and (min-width:768px) and (max-width:1023px) \{

/* style yang akan diisikan*/

\}

\section{Bootstrap Twitter (CSS Framework)}

Fluid Grid Layout atau layout relatif konsep responsive web design dengan menjaga ukuran lebar (width) agar tetap relatif terhadap viewport, hal ini berdampak pada layout yang memungkinkan untuk beradapatasi serta menyesuaikan terhadap ukuran layar (Zakir, 2016). Prinsip desain fluid adalah: 1) Jangan menggunakan height yang tetap (fix). 2) Jangan menggunakan scrollbar horizontal. 3) Pikirkan bagaimana agar media, seperti gambar dapat tampil sepenuhnya diberbagai perangkat. Teknik fluid ini merupakan teknik yang juga digunakan oleh CSS Framework Bootstrap dan Foundation untuk penerapanya di dalam desain layout web responsif.

Bootstrap Twitter merupakan kerangka frontend yang berfungsi untuk mengembangkan responsif web layout agar lebih cepat dan mudah digunakan (Zakir, 2016). Bootstrap kali pertama diperkenalkan oleh dua orang karyawan Twitter yaitu Mark Otto dan Jacob Thornton, hal ini juga yang membuat framework CSS Bootstrap lebih cepat dikenal. Dengan menggunakan konsep grid system, sehingga didalam penggunaannya mudah 
untuk dipahami. Yang harus diketahui tentang penggunaan Bootstrap adalah:

\section{Mobile First Approach}

Fokus utama Bootstrap layout didesain untuk dapat mengikuti ukuran layar ponsel.

2. Browser Support

Dukungan dari beberapa browser terkenal seperti Internet Explorer, Safari, Mozilla, Chrome dan Opera.

\section{Knowledge to get started}

Syarat dalam mempelajari Bootstrap harus terlebih dahulu memahami HTML dan CSS

4. Responsive Design

Penggunaan Bootstrap bertujuan agar layout yang dibangun dapat menyesuaikan, serta beradaptasi terhadap tampilan layar desktop, tablet dan ponsel.

Beberapa paket yang sudah built-in dari Bootstrap, diantaranya adalah, sebagai berikut:

1. Scaffolding

Struktur Bootstrap menyediakan struktur dasar dengan Grid System Model

2. CSS (Cascading Style Sheets)

Menyediakan CSS library tersendiri, yang dibuat dengan konsep media query.

\section{Component}

Bootstrap menyediakan fitur-fitur yang interaktif seperti menu dropdown, navigasi, alert, panel, dll.

4. Javascript Plugin

Fitur yang berfungsi agar layout lebih interaktif, Bootstrap sudah menyediakan Bootstrap Javascript Plugin, yang dipadukan dengan Library jQuery. Contoh dalam penggunaan slider untuk slideshow gambar.

Struktur library file yang terdapat didalam Bootstrap framewok, diantaranya: a) folder css terdapat file yang berisi file-file css, seperti file bootstrap.css. b) folder js yang berisi file-file javascript seperti file bootstrap.js. Pada Bootstrap versi 4 ini, ada beberapa file dari luar Bootstrap yang harus disertakan agar Bootstrap dapat berjalan sebagaimana mestinya. File jquery.js, yang didapatkan dari Libray jQuery serta Popper yang memuat library file popper.js

Bootstrap mengadopsi teknik grid system, untuk mengatur ukuran tampilan layar. Grid system yang berfungsi untuk membuat pengaturan dari lebar masing-masing komponen, sehingga dapat dengan mudah dan fleksibel dalam pengaplikasiannnya didalam layout web. Terdapat 12 grid yang dapat diatur sesuai dengan kebutuhan layout. Bootstrap memiliki class-prefix yang dapat digunakan, dan merespon ketika ukuran atau breakpoint pixel terpenuhi. Class prefix bootstrap terdapat empat class, diantaranya: 1) col-lg-*, akan berjalan ketika layout berada diukuran layar monitor besar. 2) col-md*, akan berjalan ketika layout berada diukuran layar sedang (default). 3) col-sm*, class prefix ini akan berjalan pada layar ukuran tablet.

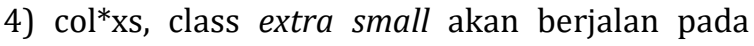
ukuran layar ponsel.

Berikut ini tampilan grid system yang terdapat pada css framework Bootstrap dapat dilihat pada Tabel 2 dibawah ini:

\begin{tabular}{|c|c|c|c|c|c|}
\hline & $\begin{array}{l}\text { Extra Small } \\
<576 p x\end{array}$ & $\begin{array}{l}\text { Small } \\
\geq 576 p x\end{array}$ & $\begin{array}{l}\text { Medium } \\
\geq 768 \mathrm{px}\end{array}$ & $\begin{array}{l}\text { Large } \\
\geq 992 \mathrm{px}\end{array}$ & $\begin{array}{l}\text { Extra Large } \\
\geq 1200 \mathrm{px}\end{array}$ \\
\hline $\begin{array}{ll}\text { Max } & \text { container } \\
\text { width } & \\
\end{array}$ & None (auto) & $540 \mathrm{px}$ & $720 \mathrm{px}$ & 960px & 1140px \\
\hline Class prefix & .col- & .col-sm- & .col-md- & .col-lg- & .col-xl- \\
\hline \# of columns & 12 & & & & \\
\hline Gutter width & $\begin{array}{l}30 p x \text { ( } 15 p x \text { on each } \\
\text { side of column) }\end{array}$ & & & & \\
\hline Nestable & Yes & & & & \\
\hline Column ordering & Yes & & & & \\
\hline
\end{tabular}

Struktur templete yang Bootstrap telah sediakan, sintaksnya akan terlihat sebagai berikut:

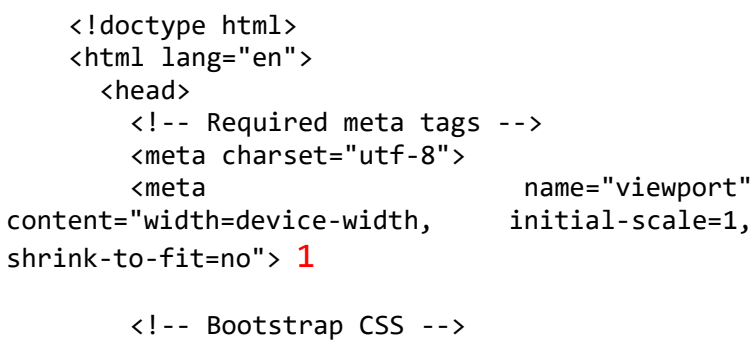

$<$ link rel="stylesheet" href="https://stackpath.bootstrapcdn.com/bootstr ap/4.2.1/css/bootstrap.min.css" integrity="sha384-

GJzZqFGwb1QTTN6wy59ffF1BuGJpLSa9DkKMp0DgiMDm4iYM

j70gZWKYbI706tWS" crossorigin="anonymous"> 2

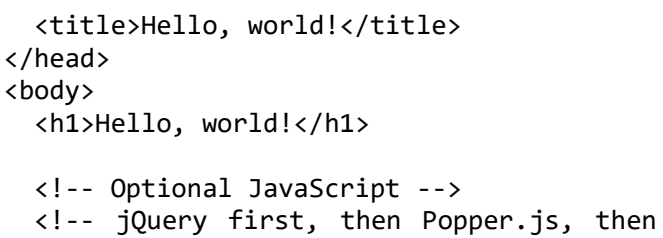


<script

src="https: //code $\cdot$ jquery $\cdot$ com/jquery -

3.3.1.slim.min.js"

integrity=" sha384 q8i/X+965Dz00rT7abK41JStQIAqVgRVzpbzo5smXKp4YfRv H+8abtTE1Pi6jizo"

crossorigin="anonymous" $\rangle\langle$ /script $\rangle \quad 3$ <script

src="https://cdnjs.cloudflare.com/ajax/libs/popp er.js/1.14.6/umd/popper.min.js"

integrity $=$ "sha384-

WHAiFfR1MFy6i5SRaxvfOCifBUQy1xHdJ/yoi7FRNXMRBu5W HdZYu1hA6ZOblgut"

crossorigin="anonymous" $\rangle\langle/$ script $\rangle$ <script

src="https://stackpath. bootstrapcdn. com/bootstra p/4.2.1/js/bootstrap.min.js" integrity="sha384BOUglyR+jN6CkvvICOB2joaf5I4l3gm9GU6Hc1og6Ls7i6U/ mkkaduKaBhlAXv9k"

crossorigin="anonymous" $></$ script $>5$ $</$ body $\rangle$

$\langle/$ html $\rangle$

Penjelasan pada skrip diatas dibaris dengan label angka 1 menjelaskan bahwa, meta tag name viewport memerintahkan kepada browser untuk menampilkan layar sesuai dengan perangkat, lebih tepatnya browser dapat beradaptasi secara otomatis, kemudian shrinkt-to-fit=no, yang berfungsi bahwa layout web tidak bisa diperbesar (zoom) dengan melakukan pinch atau ketuk pada layar, karena fitur dimatikan. Pada label dengan angka 2, menjelaskan lokasi file bootstrap.css, label dengan angka 3 sumber lokasi file jquery.js, label dengan angka 4 popper.js dan label dengan angka 5 merupakan bootstrap.js plugin. File jquery.js, popper.js dan bootstrap.js merupakan file yang berfungsi menjalankan fitur-fitur Bootstrap seperti navigasi, slider, dropdown agar layout lebih terlihat interaktif.

\section{Desain Model}

Desain mengacu kepada struktur standar sebuah website yang terdiri atas beberapa bagian, seperti header, navigasi, content, sidebar dan footer.

\section{Research/Scoping}

Penelitian ini dillakukan dengan melakukan pengamatan pada layout web yang belum menerapkan teknik layout responsif. Perancangan desain responsif ini bertujuan agar layout tradisional dapat mengakomodir dan menyesuaikan disegala perangkat baik ponsel (Hidayat, Utomo, \& Djohan, n.d.), tablet dan desktop dengan menggunakan Framework CSS Bootstrap versi 4 (empat).

2. Wireframing

Pada tahapan wireframing, mulai mendifinisikan serta melakukan perancangan terhadap pengaturan tata letak layout terhadap lebar layar (Hidayat et al., n.d.). Secara umum layout akan didesain mengikuti ukuran layar sedang (default) yaitu dekstop, kemudian tablet dan ponsel. Selanjutnya menjelaskan alur pemrograman dibelakang layar bagaimana CSS bekerja membuat layout dapat menyesuaikan ukuran layar.

Adapun yang perlu diperhatikan disaat melakukan wireframing, diantaranya: a) Menentukan grid untuk setiap layout. b) Menyiapkan file yang berkaitan dengan Bootstrap. c) Perancangan desain layout untuk setiap perangkat d) Pengujian layout.

Berikut rancangan tampilan pada desktop dengan melakukan teknik wireframing terlebih dahulu, akan terlihat pada gambar dibawah 3 ini:

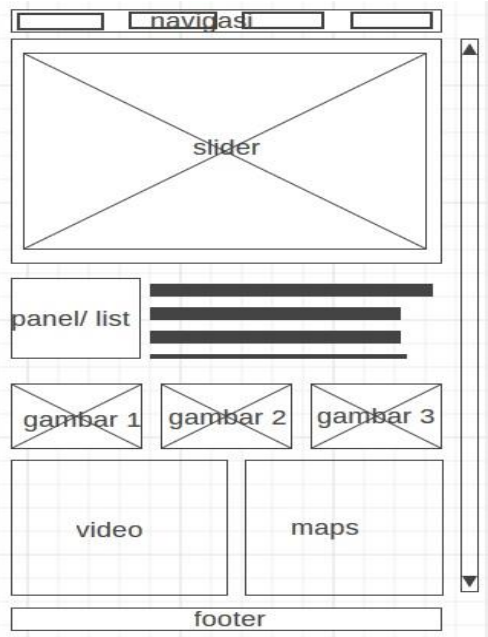

Sumber: (Santoso, 2019)

Gambar 3. Rancangan tampilan Desktop

Desain layout tersebut yang akan tampil pada ukuran layar sedang (default) yang dapat menyesuikan ukuran perangkat seperti tablet dan ponsel, untuk tampilan tablet akan terlihat pada gambar 4 dibawah ini:

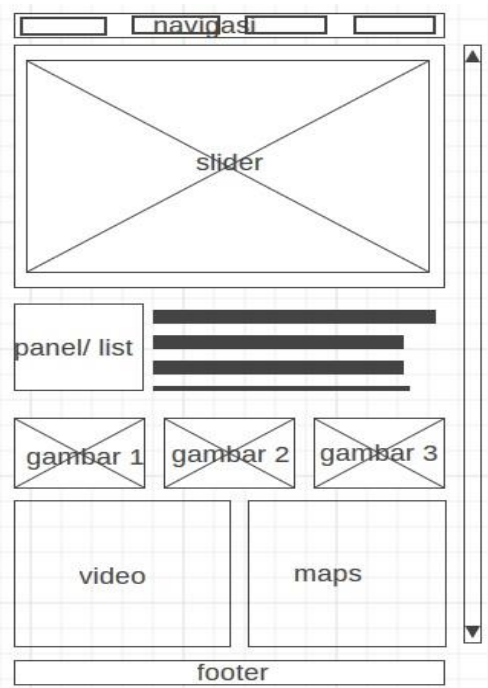

Sumber: (Santoso, 2019)

Gambar 4. Rancangan tampilan Tablet 
Disini hasil tampilan layout jika dibuka pada piranti seperti tablet, maka menu akan menyusut digantikan dengan simbol 3 bar, atau lebih dikenal dengan sebutan hamburger icon.

Hal ini akan terlihat sangat berbeda pada saat layout diakses pada layar dengan ukuran lebih kecil seperti ponsel. Layout akan ditampilkan secara keseluruhan menjadi satu kolom, jika layout semula terdapat dua kolom, disaat mode ponsel layout akan disatukan hanya satu kolom. Untuk tampilannya akan terlihat seperti pada gambar 5 dibawah ini:

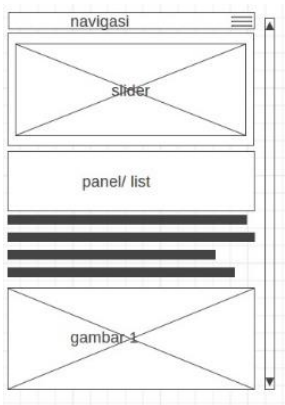

Sumber: (Santoso, 2019)

Gambar 5. Rancangan tampilan Ponsel

\section{HASIL DAN PEMBAHASAN}

Pada bagian ini akan dijelaskan seputar implementasi model dan pengujian.

A. Implementasi Model

Hasil dari perancangan desain layout web responsif dapat dilihat secara online di https://www.kursusbuatweb.com/rwd dan dapat diakses pada perangkat desktop, tablet dan ponsel. Terdapat bagian navigasi, bagian konten terdiri dari slider, beberapa baris gambar, panel pada sisi kiri dan google maps, serta video pada bagian konten bawah, sebelum footer. Layout secara otomatis beradaptasi terhadap layar pengguna, karena menggunakan CSS Framework Bootstrap. Hal ini tentunya membuat pengguna merasa nyaman, disisi lain layout Bootstrap sangat user friendly, warna tidak terlalu kontras dan tidak mencolok. Grid system yang dimiliki oleh Bootstrap membuat blok-blok div yang digunakan dalam membangun layout, akan terus beradaptasi sesuai dengan ukuran yakni 12 grid, secara keseluruhan dan grid tersebut dapat berjalan aktif pada saat class prefix Bootstrap berada pada breakpoint yang sudah ditetapkan.

Implementasi layout yang menggunakan Bootstrap Framework secara menyeluruh akan terlihat seperti pada gambar 6 berikut:

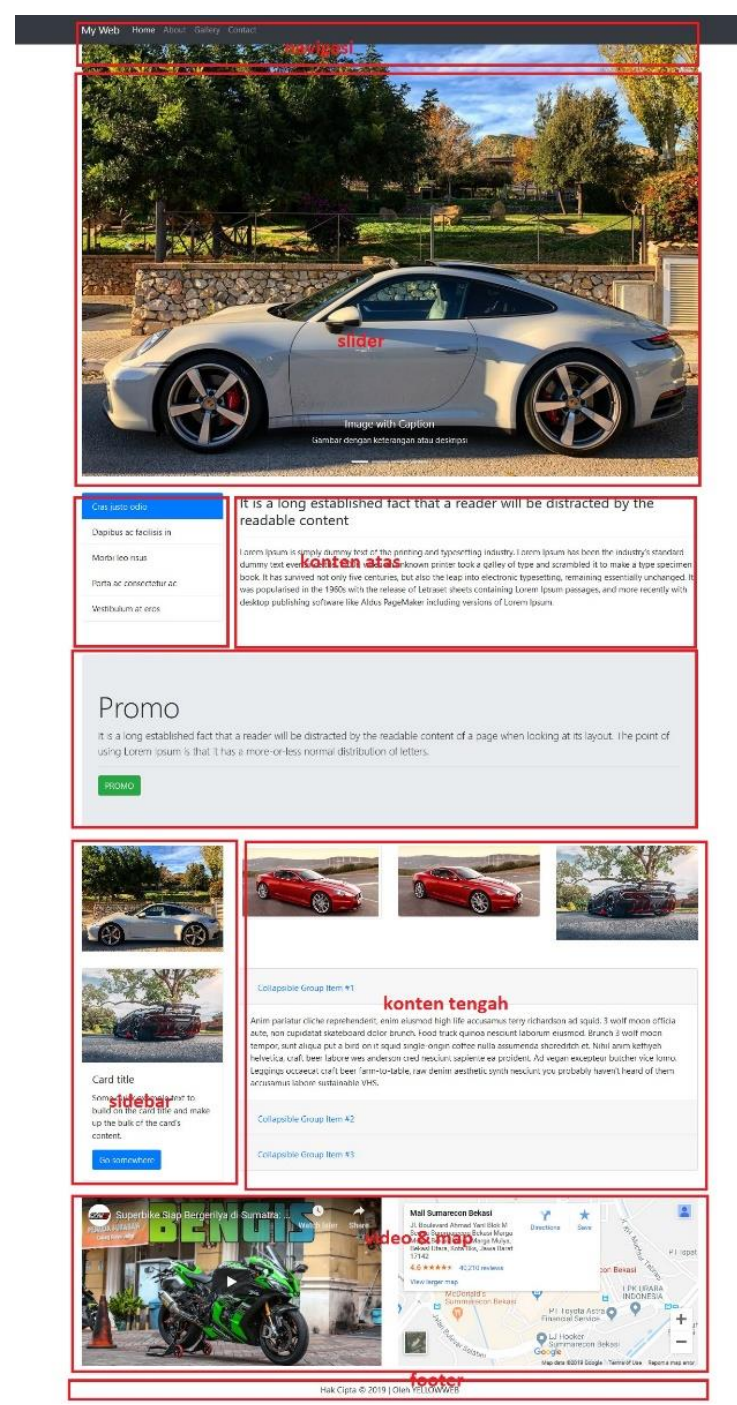

Sumber: (Santoso, 2019)

Gambar 6. Layout Web dengan Bootstrap CSS

\section{B. Pengujian}

Pada bagian pengujian dipaper ini akan diperlihatkan hasil implementasi berupa tampilan layout yang mengimplementasikan Bootstrap CSS Framework. Untuk simulasi dan ujicoba digunakan tools pendukung seperti perambahan (browser) Mozilla dan Chrome. Simulasi pada browser akan terlihat seperti pada gambar 7 dibawah ini:

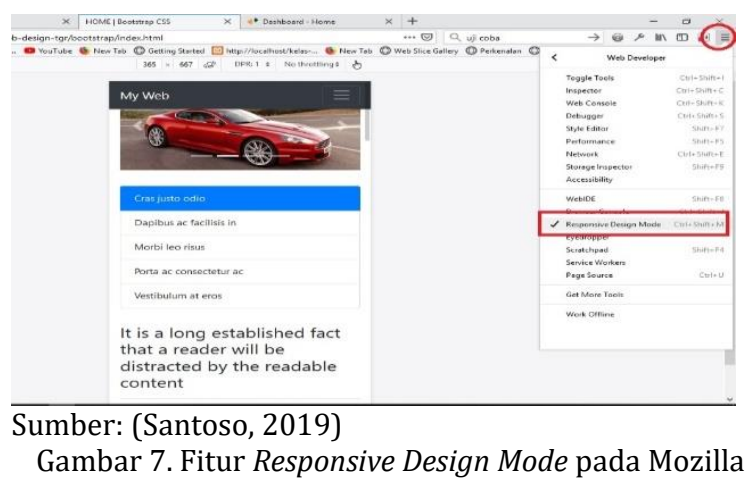


Untuk hasil ujicoba pada perangkat desktop atau laptop akan terlihat pada gambar 8 dibawah ini:

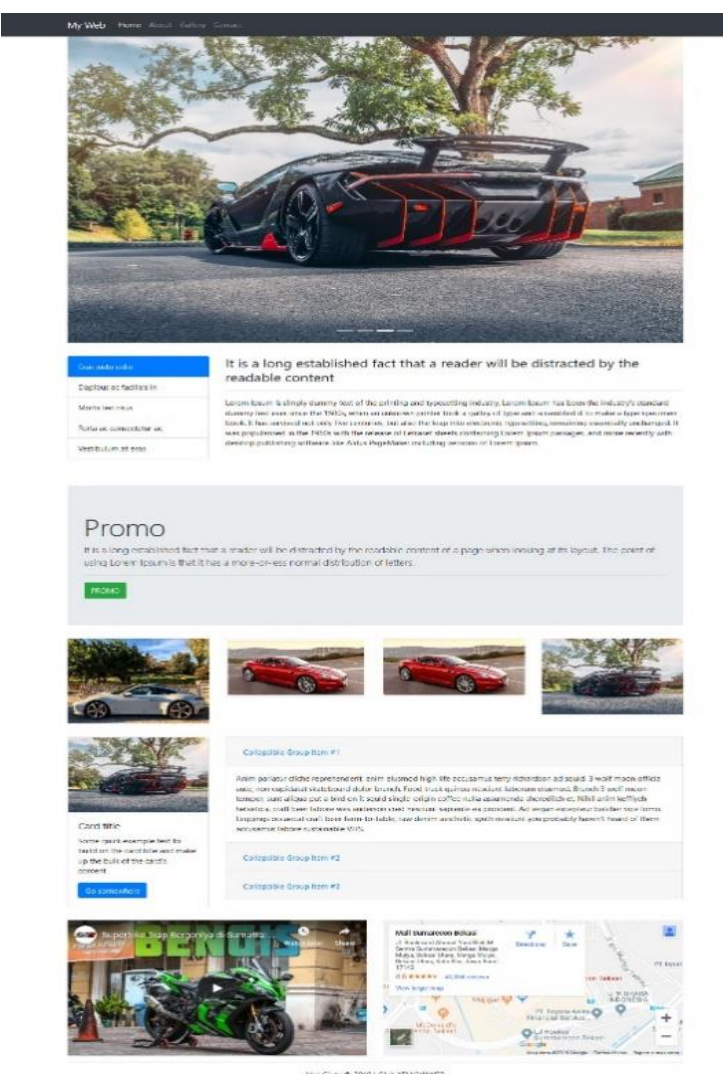

Sumber: (Santoso, 2019)

Gambar 8. Tampilan pada layar Desktop atau Laptop

Tampilan pada tablet, pada bagian (section) menu akan menyusut dan digantikan dengan ikon humberger icon tiga baris bar horizontal. Akan terlihat pada gambar dibawah 9 ini:

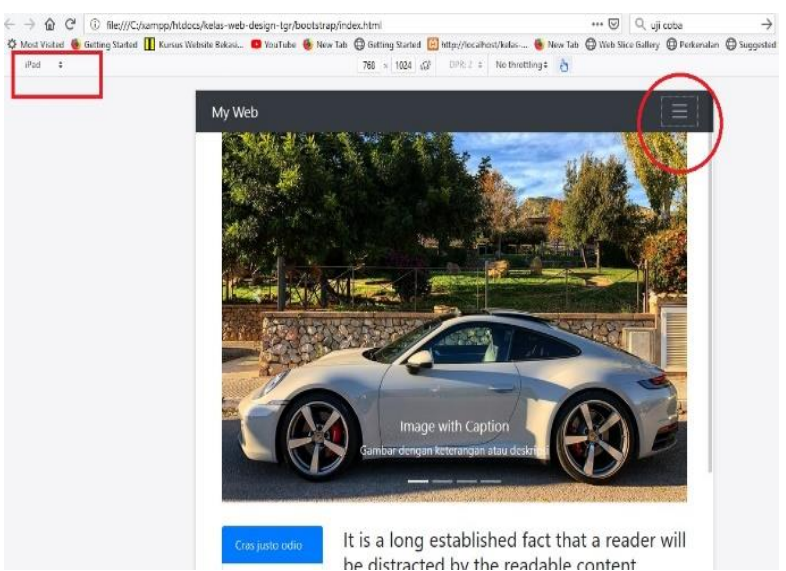

Sumber: (Santoso, 2019)

Gambar 9. Tampilan pada layar Tablet

Sedangkan tampilan yang akan terlihat pada ponsel, akan terlihat pada gambar 10 dibawah ini:

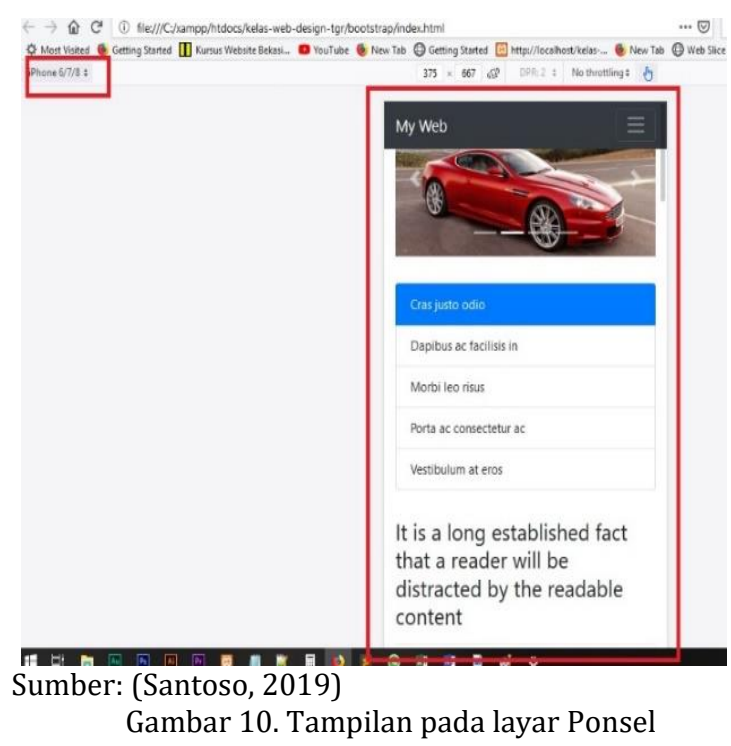

Pada gambar tersebut diatas terlihat bahwa browser Mozilla sedang menjalankan fitur responsive mode. Dengan adanya fitur tambahan tersebut, dapat menampilkan secara langsung saat dilakukan simulasi terhadap tampilan web responsif dibeberapa perangkat sekaligus.

Sedangkan tampilan yang akan terlihat pada ponsel, akan terlihat pada gambar dibawah 11 ini:

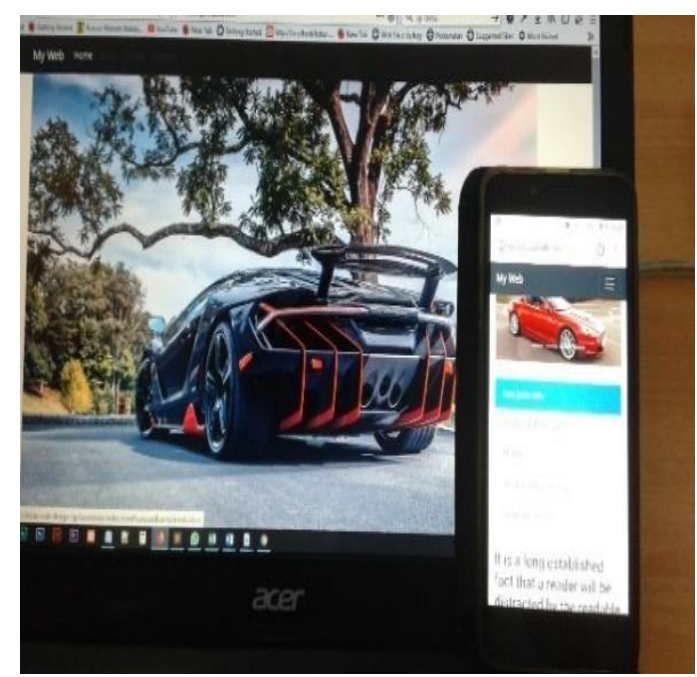

Sumber: (Santoso, 2019)

Gambar 11. Perbandingan Tampilan pada layar Ponsel dan Desktop

Terlihat perbandingan yang cukup signifikan antara layout tampilan desktop dan ponsel, namun secara estetika, layout akan tetap terjaga, serta dapat beradaptasi terhadap ukuran perangkat secara otomatis.

Hasil ujicoba dilakukan secara langsung dengan menggunakan perangkat ponsel Lenovo dengan OS Android, akan terlihat pada gambar 12 dibawah ini: 


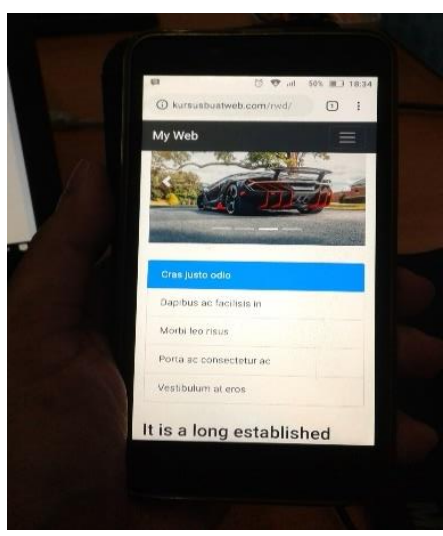

Sumber: (Santoso, 2019)

Gambar 12. Tampilan pada layar Ponsel\#2

Dengan dilakukannya ujicoba dapat dilihat bahwa dengan menggunakan Bootstrap CSS Framework hasilnya layout dapat berjalan dan bekerja secara otomatis menyesuaikan ukuran layar sesuai dengan perangkat yang digunakan. Hal ini dipengaruhi oleh media query dan viewport. Dalam implementasinya Bootstrap menggunakan Grid System, yang terdiri dari 12 kolom. Jika layout sedang dibuka pada layar ukuran ponsel, maka layout akan ditampilkan 1 kolom. Perlu diketahui pada saat membuat layout web responsif, scroll horizontal sangat dihindari, karena akan mengganggu pengguna disaat melakukan akses pada web tersebut dan meninggalkan kesan serta pengalaman (user experience) yang tidak menyenangkan. Halaman web hanya menerapkan scroll vertical pada bar sisi sebelah kanan.

Beberapa keuntungan pada saat menerapkan layout web responsif, diantaranya: 1) Dapat diakses secara mudah oleh pengguna, karena layout dapat menyesuaikan dibeberapa perangkat (multi device) sekaligus. 2) Dapat menampilkan dan memunculkan bagian tertentu secara berbeda pada perangkat. 3) Tidak memerlukan zoom, karena teks dapat terlihat dengan jelas. 4) Mudah dalam bernavigasi. 5) Efisien dan efektif, karena pengembang tidak harus membuat web dibanyak perangkat secara terpisah.

Adapun jika dilihat dari sisi kerugian dalam penerapan layout responsif ini, diantaranya: 1) Screen reader yang digunakan untuk menterjemahkan tulisan pada web, akan mengalami sedikit kendala. 2) Tidak semua browser support dengan CSS 3 seperti Internet Explorer, namun cara ini dapat disiasati dengan menggunakan JavaScript. 3) Dilihat dari sisi performance, dengan menggunakan fitur layout responsif, gambar dengan ukuran yang besar akan sedikit memperlambat pada saat dilakukan proses render halaman.

\section{KESIMPULAN}

Hasil implementasi merancang layout web responsif selain dengan menggunakan cara manual seperti penggunaan media query pada CSS, hal ini dapat dilakukan dengan menggunakan CSS Framework seperti Bootstrap. Dengan teknik grid system yang menerapkan 12 kolom pada ukuran layar, hal ini mempengaruhi cara layout menyajikan tampilan sesuai dengan ukuran perangkat, karena layout secara otomatis beradaptasi terhadap ukuran layar. Tanpa mengesampingkan fungsi dan tetap mengedepankan tampilan serta fitur terlihat sangat elegan dan intuitif.

\section{REFERENSI}

Anugerah, S. (2013). Pemodelan Responsive Web Menggunakan Foundation Framework Dalam Pengembangan Perangkat Lunak, 2013(semnasIF), 230-236.

Baturay, M. H., \& Birtane, M. (2013). Responsive Web Design: A New Type of Design for Webbased Instructional Content. Procedia - Social and Behavioral Sciences, 106, 2275-2279. https://doi.org/10.1016/j.sbspro.2013.12.25 9

Bryant, J., \& Jones, M. (2012). Responsive Web Design. Pro HTML5 Performance. https://doi.org/10.1007/978-1-4302-45254_4

Hidayat, A., Utomo, V. G., \& Djohan, H. A. (n.d.). PENERAPAN RESPONSIVE WEB DESIGN DALAM PERANCANGAN SISTEM MODUL ONLINE ADAPTIF, 44-48.

M. SOEKARNO PUTRA. (2017). Perancangan Desain Website Digital Library Universitas Bina Darma Dengan Menerapkan Responsive Web Design. Jurnal INFORMANIKA, 3(1), 2933.

Winarno, E., \& Zaki, A. (2015). Desain Web Responsif dengan HTML5 dan CSS3. PT Elex Media Komputindo.

Zakir, A. (2016). Rancang Bangun Responsive Web Layout Dengan Menggunakan Bootstrap Framework. InfoTekJar (Jurnal Nasional Informatika Dan Teknologi Jaringan), 1(1), 710.

https://doi.org/10.30743/infotekjar.v1i1.31 